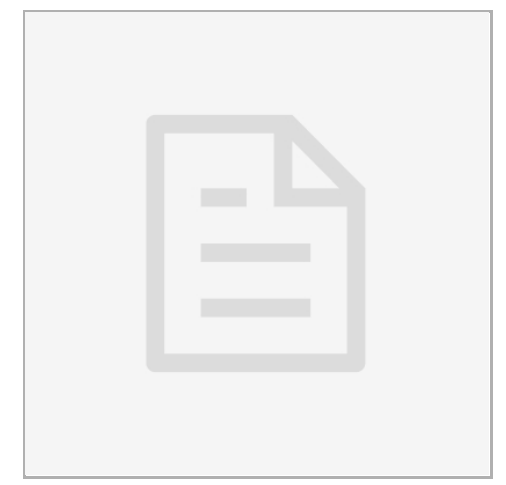

OCT 08, 2019

\section{open ठaccess}

\section{DOI:}

dx.doi.org/10.17504/protocol s.io.7xchpiw

\section{Protocol Citation: Carly} Martin, Abdul Abdul, Charles Vanderburg, Naeem Nadaf, Ashley Feirrera, Evan Macosko 2019. Frozen Tissue Nuclei Extraction (v2). protocols.io

https://dx.doi.org/10.17504/p rotocols.io.7xchpiw

License: This is an open access protocol distributed under the terms of the Creative Commons Attribution License, which permits unrestricted use, distribution, and reproduction in any medium, provided the original author and source are credited

Protocol status: Working

Created: Oct 03, 2019

Last Modified: Oct 08, 2019

PROTOCOL integer ID: 28356

Keywords: nuclei extraction, isolation, frozen, single-nuclei sequencing

\title{
(3) Frozen Tissue Nuclei Extraction (v2)
}

Abdul

Carly Martin ${ }^{1}$, Abdul $^{1}$, Ashley Feirrera ${ }^{1}$, Evan Macosko ${ }^{1}$

\section{${ }^{1}$ Broad Institute}

Human Cell Atlas Method Development Community<smiles>C1CCCCCCCC1</smiles>

Velina Kozareva

\section{ABSTRACT}

Protocol for extraction of nuclei from frozen tissue in preparation for single-nuclei sequencing (droplet-based/10X).

This protocol is based strongly on a similar extraction protocol from the McCarroll lab. 
1 Make dissociation buffer, $50 \mathrm{mLs}$ per sample:

\begin{tabular}{lllll}
\multicolumn{2}{c}{ Dissociation Media (Carter et al. 2009) } & & & \\
& MW & final concentration (mM) & for 1L (in g or ml) & for 2L (in g or ml) \\
$\mathrm{Na}_{2} \mathrm{SO}_{4}$ & 142.04 & 82 & 11.65 & 23.3 \\
$\mathrm{~K}_{2} \mathrm{SO}_{4}$ & 174.26 & 30 & 5.23 & 10.46 \\
glucose & 180.2 & 10 & 1.81 & 3.62 \\
$\mathrm{HEPES}$ & 238.3 & 10 & 2.39 & 4.78 \\
$\mathrm{MgCl}_{2} 6 \mathrm{H}_{2} \mathrm{O}$ & 203.31 & 5 & $5 \mathrm{ml}$ (1M stock) & $10 \mathrm{ml}$ (1M stock)
\end{tabular}

2 Make extraction buffer, $3 \mathrm{mLs}$ per sample:

Dissociation Buffer + 1\% Kollidon VA64 + 1\% Triton X100 + 1:40 RNase-inhibitor

3 Chill all buffers to $4 \mathrm{C}$, and keep all buffers on ice when in use.

\section{Prepare equipment:}

Set out and chill the following equipment/supplies. The instructions below are for one sample.

- Cold block dissecting tray, kept at -20C

- Chill clean razor blades and glass slides on the cold dissecting tray

- Chill $3 \mathrm{~mL}$ syringe with $261 / 2$ gauge needle, at $4 \mathrm{C}$, one syringe and needle per sample

- Place a 12-well tissue-culture plate, well-bottoms colored with marker, on ice

* Color the underside of the culture plate with dark marker so you can see your sample dissociate 
- Place $2 \mathrm{~mL}$ chilled extraction buffer in the first well of 12 -well plate

- Place $\sim 50 \mathrm{~mL}$ chilled $\mathrm{DB}$ in a falcon tube on ice

Locate DAPI (1:1000) (https://www.thermofisher.com/order/catalog/product/D1306)

- Locate $50 \mu \mathrm{m}$ eppendorf tube filter, place in $4 \mathrm{C}$

(https://us.sysmex-flowcytometry.com/consumables/celltrics-filters/sterile-single-p ackcelltrics filters/1445/sterile-single-pack-celltrics-filters-50/box?number=04-00 4-2327)

- Place $250 \mathrm{~mL}$ tubes on ice

Locate a c-Chip FR hemocytometer

\section{$5 \quad$ Locate supplies for FACS:}

- 96 well cold block, chilled to -20c:

(https://www.daigger.com/eppendorf-pcr-coolers-14616-group?gclid=EAlalQobCh MI2rKM7aDN4AIVDRgMCh2jkwRMEAQYBSABEgKeA_D_BwE)

200uL $5 \%$ BSA-DB

- 20uL collection buffer: DB with 1:40 RNAse-inhibitor

* Prepare the collection buffer right before beginning FACS session

6 Begin extraction. Perform all steps with cold buffers on ice. Nuclei should never leave the ice or $4 \mathrm{C}$ environment.

Chop up tissue on the chilled dissection tray. If your sample is a very small piece (less than $3 \mathrm{~mm}$ in any dimension) you can forgo this step and place sample immediately into the extraction buffer

Place the frozen sample on the glass slide and shave the frosty/freezer-burned tissue face you want to sample from off the sample and discard. This is damaged and not worth extracting. Then, moving rapidly but carefully, shave off "enough" sample to work with.

Rapidly mince the shaved sample with the 2 chilled razor blades that were used to shave the tissue block and scrape into the first well of a 6-well plate that contains $2 \mathrm{~mL}$ of cold extraction 
buffer. Pipette up and down 20 times.

7

Incubate in detergent with mechanical trituration:

Commence 10-min incubation, pipetting up and down 20x every $~ 2.5$ min with a 1000 uL pipette set to $1000 \mathrm{uL}$.

8 Perform mechanical dissociation:

Pull the sample into the chilled needle/syringe and express into the same well for a final mechanical dissociation.

If large chunks remain, repeat this step, pulling the sample into the same syringe and expressing it into the same well.

$9 \quad$ Large volume wash:

Extract the nuclei into empty $30 \mathrm{ml}$ tube. Add chilled DB to the extracted filtered nuclei to a total volume of just under $30 \mathrm{~mL}$.

10 Split sample:

Divide these diluted nuclei among $250 \mathrm{~mL}$ conical tubes ( $15 \mathrm{~mL}$ per tube).

11 Spin tubes at $600 \mathrm{rcf}$ in a swinging bucket centrifuge for 10 minutes at 4C. 


\section{Remove supernatant:}

Carefully aspirate $\sim 13 \mathrm{mLs}$ wash buffer with a serological pipette. To keep from disturbing pellet, gently aspirate the rest of the supernatant with a P1000 pipette. Leave about 500-300uL of sample in the bottom of the tube. Pipette sample to resuspend nuclei, being careful not to introduce bubbles. Pool the appropriate sample pairs back together.

\section{Filter nuclei clumps:}

Wet the 40um eppendorf tube filter with cold DB, pass the $\sim 0.5-1 \mathrm{~mL}$ of washed sample through the filter into an epi tube.

\section{Stain DNA:}

Add $1 \mathrm{ul}$ of DAPI to $1 \mathrm{ml}$ of nuclei. Remove $20 \mathrm{ul}$ and place into FR hemocytometer. Check your nuclei concentration and nuclei quality. Some debris is ok.

\section{FACS enrichment for singlets on singlet DAPI peak:}

We collect FACS'ed samples in PCR tubes held in a chilled (-20C) 96-well cold block to keep the collection volume as minimal as possible: (https://www.daigger.com/eppendorf-pcr-coolers14616-group?gclid=EAlaIQobChMI2rK M7aDN4AIVDRgMCh2jkwRMEAQYBSABEgKeA_D_BwE)

We FACS on a Sony SH800 sorter, using a 70um chip, with these settings: 


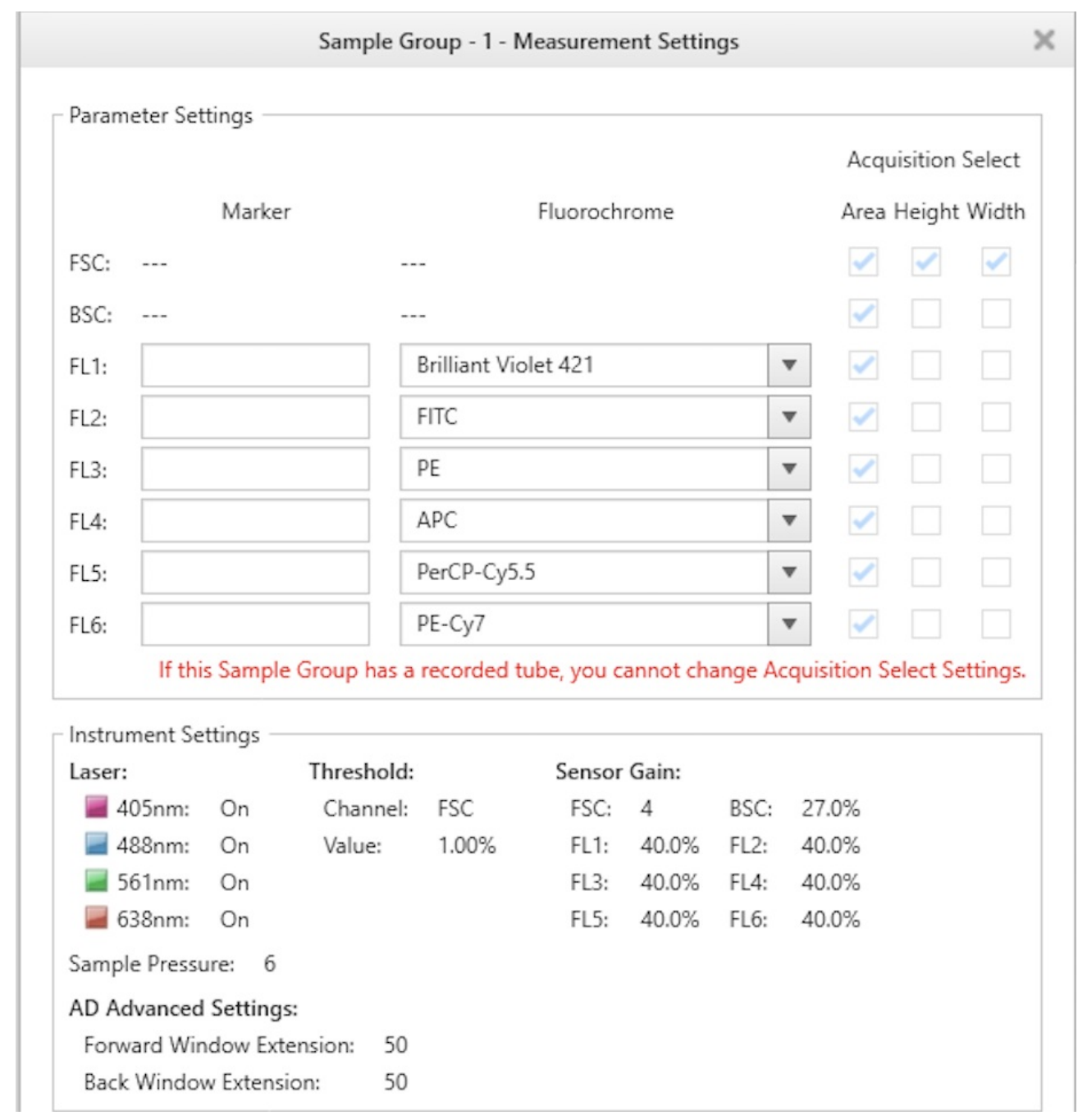

We gate on the singlet DAPI peak:

All Events

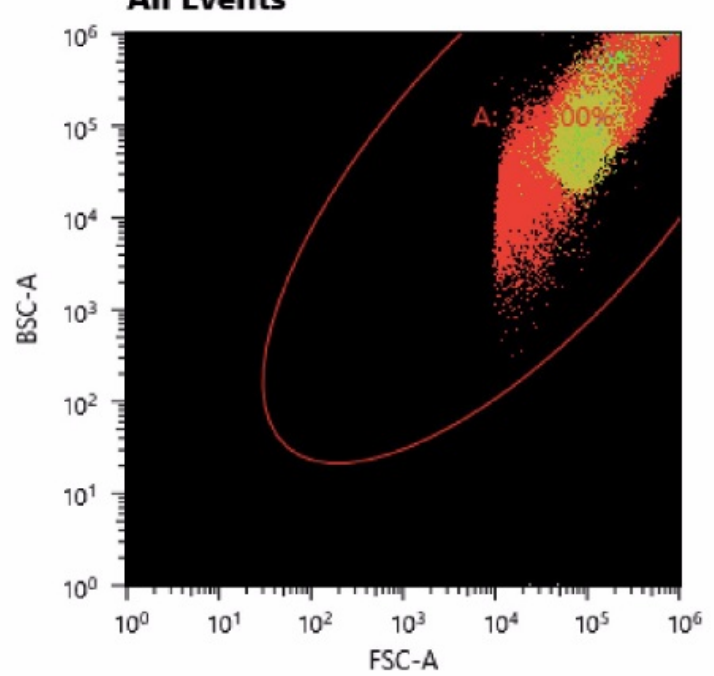

A

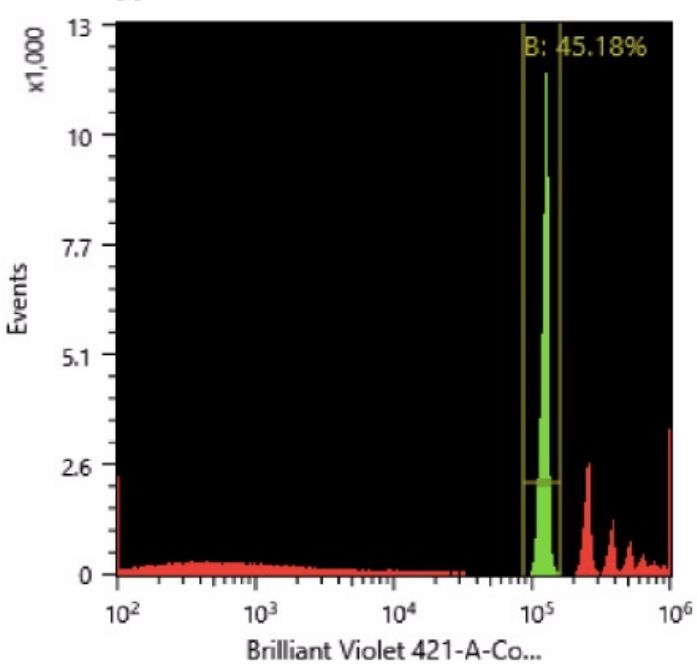


16 Prepare the collection PCR tubes:

O Fill the PCR tube with 5\% BSA-DB, vortex, and remove BSA. This coats the sides of the tube so that if nuclei hit the side of the tube they will fall to the bottom and not dry out.

Wash tube with 200 uL DB

O Make collection buffer, add 20uL collection buffer (DB with 1:40 RNase-inhibitor) to the PCR tube.

FACS into the tube using a 70um chip with $1 \%$ FSC threshold on the DAPI peak.

\section{Calculate nuclei concentration:}

After FACS, use a pipette to determine the volume in each tube.

Make a 1:10 dilution of your sample: combine 18 ul chilled DB with 2 ul of nuclei a PCR tube to make a 1:10 dilution. Mix and put into FR hemocytometer.

Visualize with the fluorescent scope, getting images of brightfield and DAPI-excited nuclei. Notice that debris is gone.

Count all 16 large squares to get the most accurate concentration estimate.Calculate the average of the 16 squares. Multiply that number by 10 (accounts for 1:10 dilution) then multiply by 5 (FC hemocytometer factor). This number is your final concentration in nuclei/uL.

\section{Prep for $10 X$ sequencing:}

The maximum nuclei you can input is 17000 (which comes out to 10000 after loss). For $10 x$ v3 the input nuclei volume is 46.6 , which means the maximum concentration you can input is 364 n/uL. 